\title{
Status of Serum Magnesium Level in Bangladeshi Children and Adolescents with Type 1 Diabetes Mellitus and its Relationship with Glycemic Control
}

\author{
*Haque $S^{1}$, Muttalib M A ${ }^{2}$, Nesa $A^{3}$, Uddin $\mathrm{MN}^{4}$, Hossain $S^{5}$, Shahabuddin $\mathrm{T}^{6}$, Tasnim $\mathrm{A}^{7}$.
}

\begin{abstract}
Type 1 diabetes mellitus is one of the most common endocrine and metabolic disorder in children and adolescents. Alteration of serum magnesium level may be associated with metabolic control and diabetic complications. The aim of the study was to evaluate serum magnesium level and find out its relationship with glycemic control in type 1 diabetic children and adolescents. For this study 80 type 1 diabetic children o adolescents with age range 1 to 18 years and 80 aged matched healthy controls were enrolled from the outpatient department of Changing Diabetes in Children, Bangladesh Institute of Research and Rehabilitation in Diabetes, Endocrine \& Metabolic disorders, General Hospital, Dhaka. Using a cross sectional design, we measured anthropometric parameters and serum magnesium level of all study subjects. We also estimate the fasting plasma glucose and HbA1c levels of the diabetic children and adolescents and controls. The mean \pm SD of serum magnesium level was significantly lower in patient with type 1 DM compared to control $(0.7 \pm 0.1$ vs $0.8 \pm 0.1 \mathrm{mmol} / \mathrm{L}$ respectively; $p=<$ 0.001). Lower level of magnesium was found in subjects with poor glycemic control compared to good glycemic control $(0.6 \pm 0.1$ vs $0.8 \pm 0.1 \mathrm{mmol} / \mathrm{L}$ respectively; $p=<0.001)$. This study showed that serum magnesium level was lowered in type 1 diabetic
\end{abstract}

1. *Dr. Shawana Haque, Assistant Professor, Department of Biochemistry, CARe Medical College, Dhaka. Mobile: 01760748156, Email: shawana. haque@yahoo.com

2. Prof. Dr. M A Muttalib, Professor \& Head, Department of Biochemistry \& Molecular Biology, BIRDEM Academy, Dhaka.

3. Dr. Ayatun Nesa, Associate Professor, Department of Laboratory Medicine, BIRDEM -2 General Hospital, Dhaka.

4. Dr. Md. Nasir Uddin, Associate Professor, Department of Clinical Biochemistry, NICVD, Dhaka.

5. Dr. Md. Sahadat Hossain, Assistant Professor, Department of Biochemistry, Prime Medical College, Rangpur.

6. Dr. Thahamina Shahabuddin, Senior Lecturer, Department of Biochemistry, United Medical College, Dhaka.

7. Dr. Aniqa Tasnim, Assistant Professor, Department of Biochemistry, Green Life Medical College, Dhaka.

*For Correspondence children and adolescents and it was strongly associated with poor glycemic control which potentially contributing to the early development of diabetic complications.

Keywords: Type 1 diabetes mellitus, serum magnesium level, glycemic control

\section{INTRODUCTION:}

Diabetes Mellitus is a major non communicable disease and a leading cause of death $\&$ disability worldwide. Type 1 diabetes mellitus (T1DM) is a disorder that arises following the autoimmune destruction of insulin- producing pancreatic beta cells. ${ }^{1,2}$ Type 1 diabetes mellitus is a chronic disease that usually develops during childhood and adolescence. Globally, the number of children ( $0-14$ years) with type 1 diabetes is $542,000 \&$ the number of newly diagnosed cases each year is $86,000 .^{3}$ The incidence of type $1 \mathrm{DM}$ in Bangladesh as 4.2 new cases $/ 100,000$ children (0-14 years) per year. ${ }^{4}$

Diabetes mellitus has been suggested to be the most common metabolic disorder associated with magnesium deficiency, having a prevalence of $25 \%$ to $39 \% .{ }^{5}$ Magnesium $(\mathrm{Mg})$ is an essential cofactor of more than 300 enzymes including those important in glycolysis, transcellular ion transport, neuromuscular transmission and synthesis of carbohydrates, proteins, lipid and nucleic acids. Numerous causes for low magnesium levels in diabetes are diets low in magnesium, osmotic diuresis that leads to high renal excretion of magnesium, insensitivity to insulin that affects intracellular magnesium transport and causes increased loss of extracellular magnesium, usage of loop and thiazide diuretics that promote magnesium wasting, diabetic autonomic neuropathies and reduced tubular reabsorption due to insulin resistance. ${ }^{6}$ Hypomagnesaemia has been implicated in various long- term complications of DM, such as increased carotid wall thickness, coronary artery disease, dyslipidemia, diabetic retinopathy, neuropathy, nephropathy, ischemic stroke and foot ulcerations. ${ }^{7,8}$ Some researchers found in their studies that hypomagnesaemia occurred in $28.2 \%$ \& $37.3 \%$ type 1 diabetic patient respectively with poor glycemic control.6,9 Oral or intravenous supplementation of magnesium in T1DM patients results in increased levels of magnesium and optimization of glycemic control. ${ }^{10,11}$

In the present study, we measured serum magnesium level in children and adolescents with T1DM and evaluated its relationship with glycemic control. 


\section{MATERIALS AND METHODS}

This was a cross sectional study conducted in the department of Biochemistry and Molecular Biology of BIRDEM-2 General Hospital from July 2016 to June 2017. The research protocol was approved by Ethical Institutional Review Board (IRB) of BIRDEM Academy, Dhaka. Total 80 type 1 diabetic patients \& 80 healthy controls aged 1-18 were selected from the outpatient department of Changing diabetes in Children (CDiC), BIRDEM-2 General Hospital. All diabetic subjects were being treated with insulin.

After selection of the subjects, the aims and objectives of the study along with procedure, risks and benefits of this study were explained to the guardian of the study subjects. When their parents were agreed for participation then an informed written consent was obtained from them and a structured questionnaire was filled up for each patient. Participants below 1 year and above 18 years, with any chronic illness and any medication that may influence serum magnesium level were excluded from the study. Detail personal, medical and family histories of the participants were recorded.

\section{Data collection technique}

Weight and height were measured (in kilogram and meter respectively) and body mass index (BMI) was calculated as weight divided by height squared. Systolic and diastolic blood pressure were also recorded. Then under all aseptic precaution $5 \mathrm{ml}$ blood sample was collected from study subjects after an overnight fasting of 8-10 hours, $4 \mathrm{ml}$ of which was delivered in a plain test tube for estimation of fasting plasma glucose, serum magnesium and remaining $1 \mathrm{ml}$ blood was delivered into EDTA tube for estimation of $\mathrm{HbA}_{1 c}$.
Serum magnesium was assessed by Beckman Coulter AU-480 auto-analyzer. Plasma glucose level was estimated by Enzymatic Glucose-Oxidase (GOD-PAP) method using Biosystem BTS 350 analyzer. Glycemic control was estimated for each patient through $\mathrm{HbA}_{1 \mathrm{c}}$ which is asessed by Clover $A_{1 c}$ analyzer using HPLC method.

To define "glycemic control", we used standard international criteria. Based on $\mathrm{HbA}_{1 \mathrm{c}}$ level, subjects were divided into two groups: (i) Those with good glycemic control (normoglycemic group), defined as $\mathrm{HbA}_{1 \mathrm{c}}$ levels < $9 \%$; and (ii) Those with poor glycemic control, defined as $\mathrm{HbA}_{1 \mathrm{c}}$ levels $\geq 9 \%$. Normal magnesium level considered as $0.7-1.0 \mathrm{mmol} / \mathrm{L}$. So, the value $<0.7 \mathrm{mmol} / \mathrm{L}$ was labeled as hypomagnesaemia.

All data were collected, tabulated and statistically analyzed using software SPSS version 20. Quantitative data was expressed as mean \pm SD and unpaired Student's 't' test was done to see the level of significance. Qualitative data were expressed as frequency \& percentage and chi-square test was done to obtain the level of significance. The p-value of $<0.05$ was considered statistically significant.

\section{RESULTS}

Table-I shows that $50 \%$ of the cases were male and $50 \%$ were female, $48.8 \%$ of controls were male and rests were female. There were no statistically significant differences in age, weight, height, BMI, systolic and diastolic blood pressure between case and controls. However, FPG and $\mathrm{HbA}_{1 \mathrm{c}}$ levels were found statistically significant between them.

Table I: General and biochemical parameters of the study population $(n=160)$

\begin{tabular}{|c|c|c|c|}
\hline Variables & Case $(n=80)$ Mean \pm SD & Control $(n=80)$ Mean \pm SD & p-value \\
\hline \multicolumn{4}{|l|}{ Gender } \\
\hline - Male & $40(50 \%)$ & $39(48.8 \%)$ & \\
\hline - Female & $40(50 \%)$ & $41(51.2 \%)$ & \\
\hline Age of the respondent & $14.9 \pm 2.9$ & $14.8 \pm 2.9$ & $>0.05^{\mathrm{ns}}$ \\
\hline Age of onset during diagnosis (in year) & $10.5 \pm 3.6$ & - & - \\
\hline Duration of diabetes (in year) & $4.5 \pm 2.7$ & - & - \\
\hline Weight of the respondent (in $\mathrm{Kg}$ ) & $50.5 \pm 16.7$ & $48.7 \pm 13.5$ & \\
\hline Height of the respondent (in $\mathrm{cm}$ ) & $150.8 \pm 13.7$ & $151.7 \pm 12.2$ & \\
\hline BMI of the respondent $(\mathrm{kg} / \mathrm{sqm})$ & $21.5 \pm 4.7$ & $20.9 \pm 3.9$ & $>0.05^{\mathrm{ns}}$ \\
\hline SBP of the respondent $(\mathrm{mm}$ of $\mathrm{Hg}$ ) & $101.0 \pm 11.6$ & $102.1 \pm 10.9$ & \\
\hline DBP of the respondent $(\mathrm{mm}$ of $\mathrm{Hg})$ & $68.2 \pm 8.1$ & $67.1 \pm 7.9$ & \\
\hline FPG $(\mathrm{mmol} / \mathrm{L})$ & $9.2 \pm 4.2$ & $5.6 \pm 0.1$ & $<0.001$ \\
\hline $\mathrm{HbA}_{1 \mathrm{c}}(\%)$ & $9.2 \pm 2.2$ & $5.6 \pm 0.1$ & \\
\hline
\end{tabular}

Data was expressed as mean $\pm \mathrm{SD}$ and comparison between groups was done by Student's unpaired ' $\mathrm{t}$ 'test. $\mathrm{n}=$ number of subjects, p-value $<0.05$ is significant, ns= not significant 


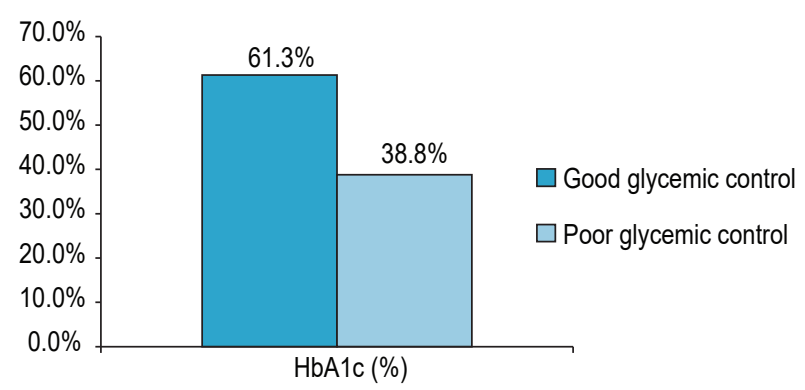

Fig.-1: Glycemic status of the diabetic children and adolescents

Figure-1 among the total diabetic children and adolescents $61.3 \%$ had good glycemic control and $38.8 \%$ had poor glycemic control.

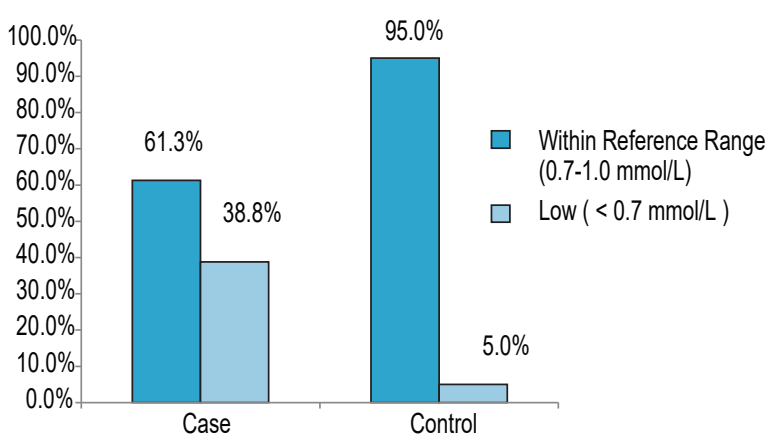

Fig.-2: Serum magnesium status of the study population

Almost $38.8 \%$ of the total participants in cases and $5.0 \%$ of controls had hypomagnesaemia as shown in Figure 2.

Table II shows significantly lower level of serum magnesium $(0.7 \pm 0.1)$ in cases with T1DM compared to controls. The serum magnesium level was significantly lower $(0.6 \pm 0.1)$ in patient with poor glycemic control compared to good glycemic control which was also shown in table-II.

Table-II: Comparison of serum magnesium level in study population $(n=160)$ and relationship of serum magnesium level with glycemic status in cases $(\mathbf{n}=\mathbf{8 0})$

\begin{tabular}{|l|l|c|c|}
\hline \multicolumn{2}{|l|}{ Variable } & p- value \\
\hline Serum magnesium $(\mathrm{mmol} / \mathrm{L})$ & Case & $0.7 \pm 0.1$ & $<0.001$ \\
\cline { 2 - 4 } & Control & $0.8 \pm 0.1$ \\
\cline { 2 - 4 } & In good glycemic control $\left(\mathrm{HbA}_{1 \mathrm{c}}<9\right)$ & $0.8 \pm 0.1$ \\
\cline { 2 - 4 } & In poor glycemic control $\left(\mathrm{HbA}_{1 \mathrm{c}} \geq 9 \%\right)$ & $0.6 \pm 0.1$ \\
\hline
\end{tabular}

Data was expressed as mean \pm SD and comparison between groups was done by Student's unpaired 't' test. $\mathrm{n}=$ number of subjects, p-value $<0.05$ is significant, ns= not significant

Table III shows the serum magnesium level in cases; it was significantly lower in patients who have duration of diabetes mellitus more than 5 years compared to those who have duration of diabetes mellitus less than that.

Table -III: Relationship of duration of DM with serum magnesium level in cases $(\mathbf{n}=\mathbf{8 0})$

\begin{tabular}{|l|l|c|c|c|}
\hline Variables & & \multicolumn{2}{|c|}{ Relationship with duration of DM } & p-value \\
\hline & & $<5$ years & $\geq 5$ years & \\
\hline Serum magnesium & Low $(<0.7 \mathrm{mmol} / \mathrm{L})$ & $12(38.7 \%)$ & $19(61.3 \%)$ & $<0.001$ \\
\hline & Within reference range & $39(79.6 \%)$ & $10(20.4 \%)$ & \\
\hline & $(0.7-1.0 \mathrm{mmol} / \mathrm{L})$ & & & \\
\hline
\end{tabular}

Statistical analysis was done by Chi-square test to compare among the groups. $\mathrm{n}=$ number of the subjects, $\mathrm{p}$-value $<0.05$ is significant, ns= not significant 


\section{DISCUSSION}

In the present study we measured serum magnesium level, as well as other clinical and biochemical parameters, in children and adolescents with T1DM. Inadequate metabolic control can affect the concentrations of magnesium, developing hypomagnesaemia, which may be directly related with some micro and macrovascular complications observed in diabetes, as cardiovascular disease, retinopathy and neuropathy. ${ }^{12}$

In this study, we estimated serum magnesium level in children and adolescents with T1DM. Taking cut off level of serum magnesium $<0.7 \mathrm{mmol} / \mathrm{L}$, we detected $38.8 \%$ of diabetic patient had hypomagnesaemia which is significantly lower compared to control. A recent study in Egypt showed that there were $37.3 \%$ of the diabetic subjects had hypomagnesaemia. ${ }^{9}$ Seyoum et al. ${ }^{13}$ found a higher percentage of hypomagnesaemia (65\%) in their study. Contrary to our result, Zargar et al. ${ }^{14}$, did not found any significant alteration in plasma magnesium level in type 1 diabetes mellitus.

We also found that serum magnesium was significantly lower $(<0.001)$ in patient with poor glycemic control compared to good glycemic control. In poor glycemic control uncontrolled hyperglycemia and glycosuria may increase magnesium excretion through osmostic diuresis. This result is similar with the study of many researchers. ${ }^{6,9,15,16}$ Inconsistent with our result, some researchers did not observe any relationship between serum magnesium and glycemic status ${ }^{17-19}$. This difference could be attributed to the difference in study populations, degree of diabetic control among them and to the different methods of evaluating serum magnesium and $\mathrm{HbA}_{1 \mathrm{c}}$.

In our study we found serum magnesium was low with patient having duration of $\mathrm{DM} \geq 5$ years. This result is consistent with Shahbah et al. ${ }^{6}$ who found that duration of diabetes were more in participants with hypomagnesaemia.

\section{CONCLUSIONS}

Present study demonstrated a significantly lower serum magnesium level in T1DM cases and a low serum magnesium level was associated with poor glycemic control. So, it is advocated that proper glycemic control, close monitoring, supplementation of magnesium might be beneficial for preventing complications in type 1 diabetic children and adolescents.

Conflict of interest: The authors declare no conflict of interest.

\section{REFERENCES}

1. Atkinson MA, Eisenbarth GS. Type 1 diabetes: new perspectives on disease pathogenesis and treatment. Lancet. 2001; 358:221-9.

2. Bluestone JA, Herold K, Eisenbarth G. Genetics, pathogenesis and clinical interventions in type 1 diabetes. Nature. 2010; 464:1293-300.

3. The global picture.IDF Diabetes Atlas. 2015; 7th ed.47-63.

4. The global burden and regional overviews. IDF Diabetes Atlas. 2013; 6th ed. 29-68.

5. Rude RK. Magnesium deficiency and diabetes mellitus. Causes and effects. Postgrad Med. 1992; 92:217-24.

6. Shahbah D, El Naga AA, Hassan T, Zakaria M, Beshir M, Al Morshedy S, et al. Status of serum magnesium in Egyptian children with type 1 diabetes and its correlation to glycemic control and lipid profile. Medicine. 2016; 95(47):1-7

7. Pham PC, Pham PM, Pham SV, Miller JM, Pham PT. Hypomagnesemia in patients with type 2 diabetes. CJASN. 2007; 2(2):366-73.

8. Sakaguchi Y, Shoji T, Hayashi T, Suzuki A, Shimizu M, Mitsumoto K, et al. Hypomagnesemia in type 2 diabetic nephropathy: a novel predictor of end-stage renal disease. Diabetes care. 2012; 35 (7), 1591-7.

9. Asmaa MN, Samira SZ, Aliaa MM, Bassem HG. The Relationship between Hypomagnesaemia and Glycemic Control in Children with Type 1 Diabetes Mellitus. J Diabetes Metab. 2016; 7(8): 1-5.

10. Yeh GY, Eisenberg DM, Kaptchuk TJ, Phillips RS. Systematic review of herbs and dietary supplements for glycemic control in diabetes. Diabetes care. 2003; 26(4):1277-94.

11. Shahbah D, Hassan T, Morsy S, El Saadany H, Fathy M, Al-Ghobashy A, et al. Oral magnesium supplementation improves glycemic control and lipid profile in children with type 1 diabetes and hypomagnesaemia. Medicine. 2017; 96(11): 1-6.

12. Sales CH, Pedrosa LD. Magnesium and diabetes mellitus: their relation. Clinical Nutrition. 2006; 25(4):554-62. 
13. Seyoum B, Siraj ES, Saenz C, Abdulkadir J. Hypomagnesemia in Ethiopians with diabetes mellitus. Ethnicity and disease. 2008; 18(2):147-51.

14. Zargar AH, Bashir MI, Masoodi SR, Laway BA, Wani AI, Khan AR, et al. Copper, zinc and magnesium levels in type-1 diabetes mellitus. Saudi Med J. 2002; 23(5):539-42.

15. Galli-Tsinopoulou A, Maggana I, Kyrgios I, Mouzaki K, Grammatikopoulou MG, Stylianou C, et al. Association between magnesium concentration and HbA1c in children and adolescents with type 1 diabetes mellitus . J. Diabetes. 2014; 6(4):369-77.

16. Shaikh M, Devrajani B, Soomro A, Ali Shah S, Devrajani T, Das T. Hypomagnesemia in Patients with
Diabetes mellitus. World Appl. Sci. J. 2011; 12(10) :1803-6.

17. Lin CC, Tsweng GJ, Lee CF, Chen BH, Huang YL. Magnesium, zinc, and chromium levels in children, adolescents, and young adults with type 1 diabetes. Clin. Nutr. 2016; 35(4):880-4.

18. Salmonowicz B, Krzystek-Korpacka M, Noczynska A. Trace elements, magnesium, and the efficacy of antioxidant systems in children with type 1 diabetes mellitus and in their siblings. Adv Clin Exp Med. 2014; 23(2):259-68.

19. Matthiesen G, Olofsson K, Rudnicki M. Ionized magnesium in Danish children with type 1 diabetes. Diabetes care. 2004; 27(5):1216-7. 